\title{
The impact of land use characteristics for sustainable mobility: the case study of Rome
}

\author{
Stefano Gori • Marialisa Nigro • Marco Petrelli
}

Received: 31 March 2011 / Accepted: 21 February 2012 / Published online: 14 March 2012

(C) The Author(s) 2012. This article is published with open access at SpringerLink.com

\begin{abstract}
Background Sustainable mobility requires actions to reduce the need for travel, to promote modal shift, to reduce trip lengths and to increase efficiency of transport system. Public transport could play an important role to solve part of the needs previously reported. Starting from these remarks, the present paper analyse the role, the importance and the impact of land use characteristics to develop services able to compete with automobile use. This analysis is carried out by studying the real world case of the city of Rome in Italy.

Results The results of the test carried out highlight the importance of density of residences and activities, the need for a good quality access system to the transit services stops and the importance of the configuration of the transit network, identifying the best way to connect the different districts of the urban area. However, single actions are not sufficient to achieve a sustainable transport system: these actions can be successful only if they are planned in a complex unique system that helps the synergic development of the effects of the single actions proposed.
\end{abstract}

Keywords Sustainable mobility · Land use - Urban transport $\cdot$ Public transport

S. Gori $\cdot$ M. Nigro $(\bowtie) \cdot$ M. Petrelli

Department of Civil Engineering, Roma Tre University,

Via Vito Volterra 62,

00146, Rome, Italy

e-mail: mnigro@uniroma3.it

S. Gori

e-mail: sgori@uniroma3.it

M. Petrelli

e-mail: mpetrelli@uniroma3.it

\section{Introduction}

Recently important changes in urban features strongly modified the quantity and the quality of the mobility system: the continuous spread of residences and activities have increased the length of trips and the use of private transport; the usual mobility habits have been changed by more complex behaviours (trip chaining). The automobile is often considered the only transport mode while transit became less and less used with strong impacts on environment and sustainability.

These changes are mainly due to the results of the evolution of urban areas according to the different stages of development of the transport modes technology: the first stage is known as "urban concentration" with small urban area characterized by high density; the second stage is the "suburbanization" in which the city centre cannot accept further demand of residences and activities and so conurbations start to grow up; the last stage is based on the urban decentralization. Newman and Kenworthy [17] describe this trend as the transfer from "pedestrian cities" to the modern "automobile city". The "pedestrian cities", characterized by a unique compact nucleus, have been developed until the middle of the XIX century in Europe; afterwards there is a shift toward building small centres localized along the main railway systems ("transit oriented cities"). Starting from 1940 until now, metropolitan areas are converted into the contemporary "automobile city", where dispersion of activities and residences on the territory, a road network that moves further away from a grid structure, and the big spaces that separates buildings, make the private vehicle the only possible method of transportation.

The resulting phenomena are related particularly to congestion, implying an increase of travel times, an increase of air and noise pollution, excessive production of greenhouse gases and land consumption. Such occurrences are clearly not consistent with sustainable issues. Instead, these require actions to 
reduce the need for travel, to encourage modal shift, to reduce trip lengths and to increase efficiency of transport system. Public transport could play an important role to solve part of these needs. Starting from these remarks, the present paper wants to analyse the role, the importance and the impact of land use characteristics to develop services able to compete with automobile use. This analysis is carried out by studying the real world case of the city of Rome, Italy.

This paper is structured in five sections including this introduction; the second section analyses the literature and some remarkable examples of sustainable mobility in the world; the third section shows the impacts of different elements on the demand modal split and introduces criteria to improve the transit system in the case of the city of Rome while the fourth section carries out a detailed analysis about roman urban structure to better understand the results of the previous section; the fifth and last section contains observations and final considerations about the importance of the interaction between land use policy and transportation planning.

\section{Literature review on land use and transport interaction}

The interaction between land-use and the transport system has been heavily dealt with by the research community recently and, in this section, the literature review represents the synthesis of some interesting analysis about this interaction focusing on the relationships between land use characteristics (such as urban densities, neighborhood design schemes and mixed land-use) and transit ridership. This is a very controversial topic because different thesis are already present: some studies establish that such variables seem to have an impact on auto ownership and use, but other studies quantify the impact as, at best, marginal. Literature review about transportation and land-use interaction can be found in Badoe and Miller [2] and also in Ewing and Cervero [12]. The reviews are conducted to understand if travel variables as trip frequencies, trip lengths and mode choices are correlated with the built-in environment in the studies analyzed. The studies provide an example of the complexity of the connection between landuse and transport system, involving a very large number of social, economic, technical and historical elements not easy to measure and to compare.

About the opportunities provided by the public transport systems to develop a sustainable mobility, Bernick and Cervero [7] and Cervero [10] show, introducing the concept of the "transit metropolis", examples of transit services that provide respectable alternatives to travel by car. This is the case of Zurich and Melbourne, where the cities are formed by a unique central and compact business area or Stockholm and Copenhagen, where new urban areas have appeared concentrated around railway stations connencting them with the historic central nucleus. In other cases, accepting spread-out and lower density areas, it has been chosen to appropriately adapt transit services even through the help of new technologies as track-guided buses or small vehicles ("adaptive" public transport). This is the case of cities like Adelaide and Mexico City (Fig. 1).

In the case of Munich, Ottawa and Curitiba it was chosen to realize an efficient transit system through "hybrid schemes". These try to balance concentration of urban development, along the main corridors of the public transport services, and adapting transit services to serve the spread-out suburbs (Fig. 2). All these examples of transit success are characterized by strong interactions between the land use policy and the transport system planning.

Similar conclusions are made also by Beimborn et al. [6] about the requirements for successful transit. Land use design could be sensitive to transit needs to develop "transit corridors" divided by $0.4-0.8 \mathrm{~km}$ from the automobile networks, in order to separate the automobile oriented land-use from the transit oriented land-use. Such areas would have a mix of land uses and higher densities to reach a concentration of trip ends along the transit service, with a high quality access system to transit stops. The importance of a high quality access system to transit stops is underlined also by Schlossberg and Brown [19].

Extensive debates are also related to the role played by the population and activities densities to explain the level of car and public transport use. Sinha [20] demonstrates, with the collection of different data from 46 cities in United States, Australia, Canada, East Europe and Asia, that an high urban population density seems to be a primary element to increase transit boardings. These results are reported in Fig. 3, where the transit boardings per capita per year increase with the rise of the number of persons per hectare, while the car kilometres of travel per capita per year decrease with the rise of the number of persons per hectare.

About the impact of the density, an important observation is highlighted by Eidlin [11]. According to this contribution,

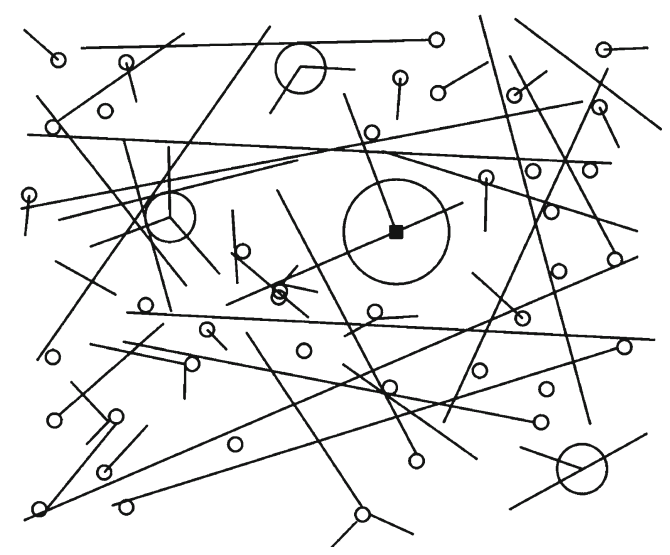

Fig. 1 Adaptive public transport. Source: Cervero [10] 


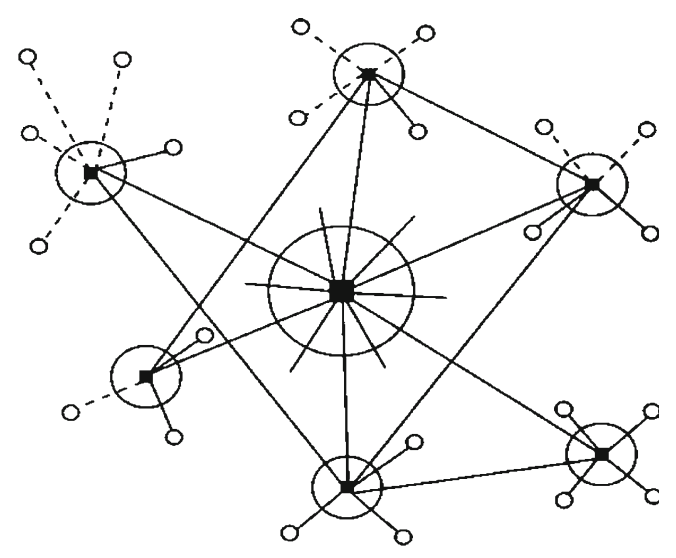

Fig. 2 Hybrid scheme. Source: Cervero [10]

the critical issue is not the density values, but its distribution within an urban area. This consideration derives from the analysis of the city of Los Angeles that is characterized by an average density of activities and residences higher than many other Americans cities, but these values are correlated with one of the lower levels of transit share. The comparison with the data of New York and San Francisco, characterized by the largest level of transit use in the US but by an average value of population density lower than Los Angeles, permits to underline that this condition derives from the low variation of population and activities density within the territory, that is what the author defines as "the worst of all worlds".

Mees [16], from the comparison between urban densities and transport mode shares of Australian, Canadian and United States urban areas, highlights the following results: Australian cities, that have similar densities to those of Canadian cities and the more densely-populated US cities, report variations in density with little or no relationship to transport modes share, which seems more closely related to different transport policies. These findings are very different from those on which current urban policies are based, and suggest the need for a radical rethinking of those policies.

Other interesting contribution about the determinants of the mode choice is from Buehler [8] with the comparison of the results of national travel surveys in Germany and in the USA. Germans are considerably more likely to walk, bike, and use public transport than Americans even if socioeconomic, demographic and spatial development variables are quite similar. Travel behaviour choice seems to be more related with other factors such as transport and land-use policies as well as cultural preferences.

Facchinetti [13] describes a series of operations, adopted in the last years in some American cities, for the renovation of the areas surrounding the main transit rail stops. These operations are based on restoring and increasing (urban) density in order to realize a compact nucleus that can be self-sufficient, with all the necessary activities, with a welldesigned pedestrian network and with the presence of different social categories living together.

Sung and Oh [21], analysing the association between transit-oriented development and transit ridership in Seoul, suggest focusing the attention more than in increasing density in strengthening the transit service network, growing the mixed land-use and creating a more pedestrian friendly surrounding around rail stations working on urban design and street networks.

A synthesis of the main characteristics that could identify a sustainable city are made by Banister [3-5] especially for the European context, where the scarcity of space and the protection of not built-up space are key issues. The total amount of population level (ranging from 50.000-100.000 inhabitants) has to be distributed so as to guarantee medium densities (40200 persons per hectare), as shown by empirical studies. The city should also present mixed use developments mainly
Fig. 3 Impact of density on transit and private transport demand. Source: Sinha [20]

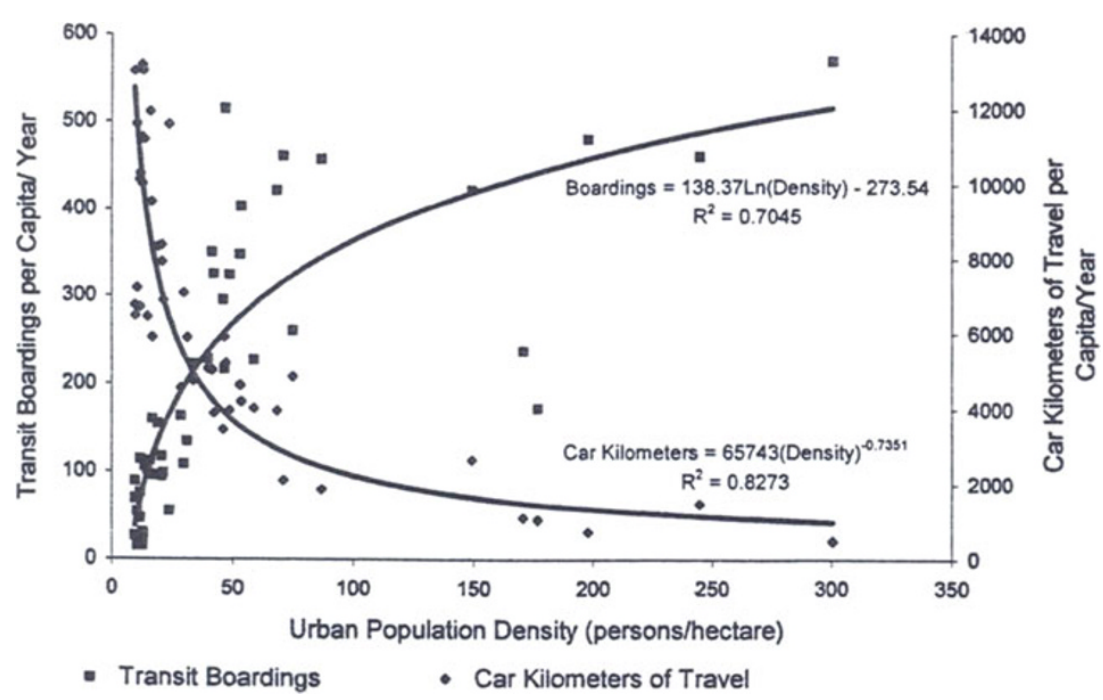




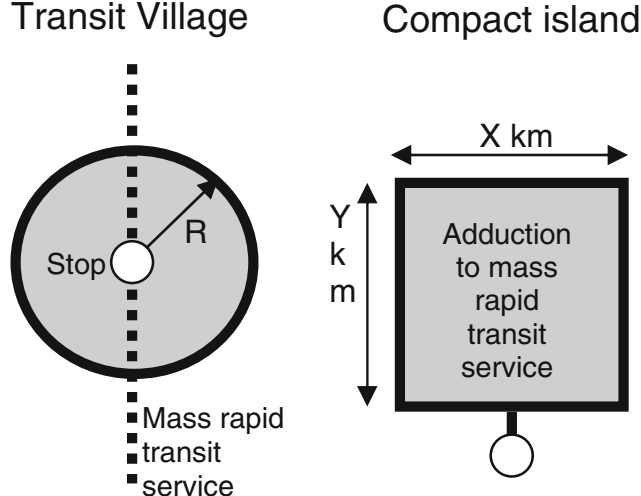

Fig. 4 Possible transit oriented development (TOD). Source: Gori et al. [14]

oriented to public transport accessible corridors and near to highly public transport accessible interchanges. Moreover Banister underlines the importance of the implementation of appropriate policies in order to develop high-quality liveable cities to be the basis for sustainable urban development.

Gori et al. [14] define two possible transit oriented development (TOD, Fig. 4) to better use a rapid mass transit service (high speed and high capacity transit system, usually a rail system):

1. transit-village: with a strong concentration of activities and residences in an area of about $500 \mathrm{~m}$ of radius (considered as the maximal pedestrian distance);

2. compact island: with lower densities, different possible configurations and a maximum extension of about 300 400 ha (roughly a 2 by $2 \mathrm{~km}$ area), in which the access to the mass rapid transit system is guaranteed by the introduction of an effective feeder public transport service which ensures a large area coverage as well.

While the first TOD suggested is the classic transit village, proposed firstly by Calthrope [9], the second one is proposed by the authors and derived from the analysis of the Italian city of Venice where travel is possible, without particular problems, using ferry services along the main city canal and walking. In both cases the access phase to the mass rapid transit system becomes fundamental. In fact accessibility can penalize the "door-to-door" speed, increasing the total travel time. For the "transit village", the access phase has to be identified at the pedestrian level working on the configuration of the road network (in fact the road network is also the network used by pedestrians, [18]), while for the "compact island" the problem becomes to identify the optimal layout of transit routes balancing directness and service coverage.

\section{The Rome case study}

In the previous sections, different elements, criteria and policies have been underlined as important components to build a competitive public transport system and therefore a more sustainable urban development. In this section, two different approaches (improving the transit system performance and modifying the land use characteristics) are implemented for the case study of the city of Rome with the final aim of analysing the impacts of these actions on the demand modal split.

The urban area of Rome is characterized by a population of 2.6 millions with 1.1 millions employees, contributing to about 552,000 trips in the morning peak hour. A first division of the city can be done considering areas to be inside or outside the GRA (a circular freeway of approximately $68 \mathrm{~km}$ of length). Inside the GRA, the average population density is not high (about 70 persons/ha) and a similar measure is obtained in terms of the average employee density (about 75 employees/ha). Outside the GRA, in a very large area (about 90,000 ha) the density decreases to very low values of 6 persons/ha and 1.5 employees/ha even if the population of this external area is larger than half a million. In terms of employees, about half of the total amount are distributed in the peripheral districts, also situated outside of the GRA.

In regard to the transit system, there are two metro lines extending for a total of $36 \mathrm{~km}$. These lines are radial with a unique interchange in the city centre (Termini rail station). Other seven rail lines connect the surrounding urban areas to the city centre, but these services are actually far from frequent and only three of them present an headway lower or equal than $15 \mathrm{~min}$ in the morning peak hour. The union of five of these rail lines creates an half circle inside the GRA known as the "rail ring".

Urban bus transport develops for 2,263 km [1] with 315 frequency service lines, 39 fixed-time service lines, and 11

Table 1 Infrastructural scenario for the Roman urban area

\begin{tabular}{llllll}
\hline State & $\begin{array}{l}\text { Number of metro } \\
\text { lines [km] }\end{array}$ & Transit corridors & $\begin{array}{l}\text { Population in } \\
\text { the metro basin }\end{array}$ & $\begin{array}{l}\text { Trips attracted } \\
\text { by metro basin }\end{array}$ & $\begin{array}{l}\text { Increase of transit } \\
\text { modal split }\end{array}$ \\
\hline Ref. 2010 & $2[36]$ & - & 436.000 & 148.000 & - \\
Scenario 1 (Project 2020) & $4[76]$ & 11 & 2.186 .600 & 367.500 & $+5 \%$ \\
\hline
\end{tabular}


Table 2 Land use scenarios for the Roman urban area

\begin{tabular}{lllll}
\hline State & $\begin{array}{l}\text { Number of metro } \\
\text { lines }[\mathrm{km}]\end{array}$ & Transit corridors & $\begin{array}{l}\text { TOD [numbers, } \\
\text { served trips] }\end{array}$ & $\begin{array}{l}\text { Increase of transit } \\
\text { modal split }\end{array}$ \\
\hline Ref. 2010 & $2[36]$ & - & - & - \\
Scenario 2 $(2020)$ & $4[76]$ & - & {$[12$, generation $]$} & $+4 \%$ \\
Scenario 3 (2020) & $4[76]$ & - & {$[5$, attraction $]$} & $+5 \%$ \\
\hline
\end{tabular}

express lines. The express lines connect peripheral districts to the city centre through a radial service as well. However, corridors used by express lines are usually shared with private traffic or other type of public transport services, thus reducing their operating speed and reliability. The other bus lines are based on an extensive rather than intensive service, with low-medium frequency lines and a very large service coverage.

In regard to private transport, Rome has a very high level of automobile ownerships (more than 700 for 1,000 persons) and the road network is frequently congested. Large part of the historical centre of the city, one of the main point of concentration of activities, is a traffic limited zone (ZTL) and the access in the area is permitted only to the residents cars. In many districts of the inside city, there is a relevant lack of space for parking; this trouble is partially offset by an extensive use of motorcycles.

The transit share nowadays is estimated to be around $30 \%$.
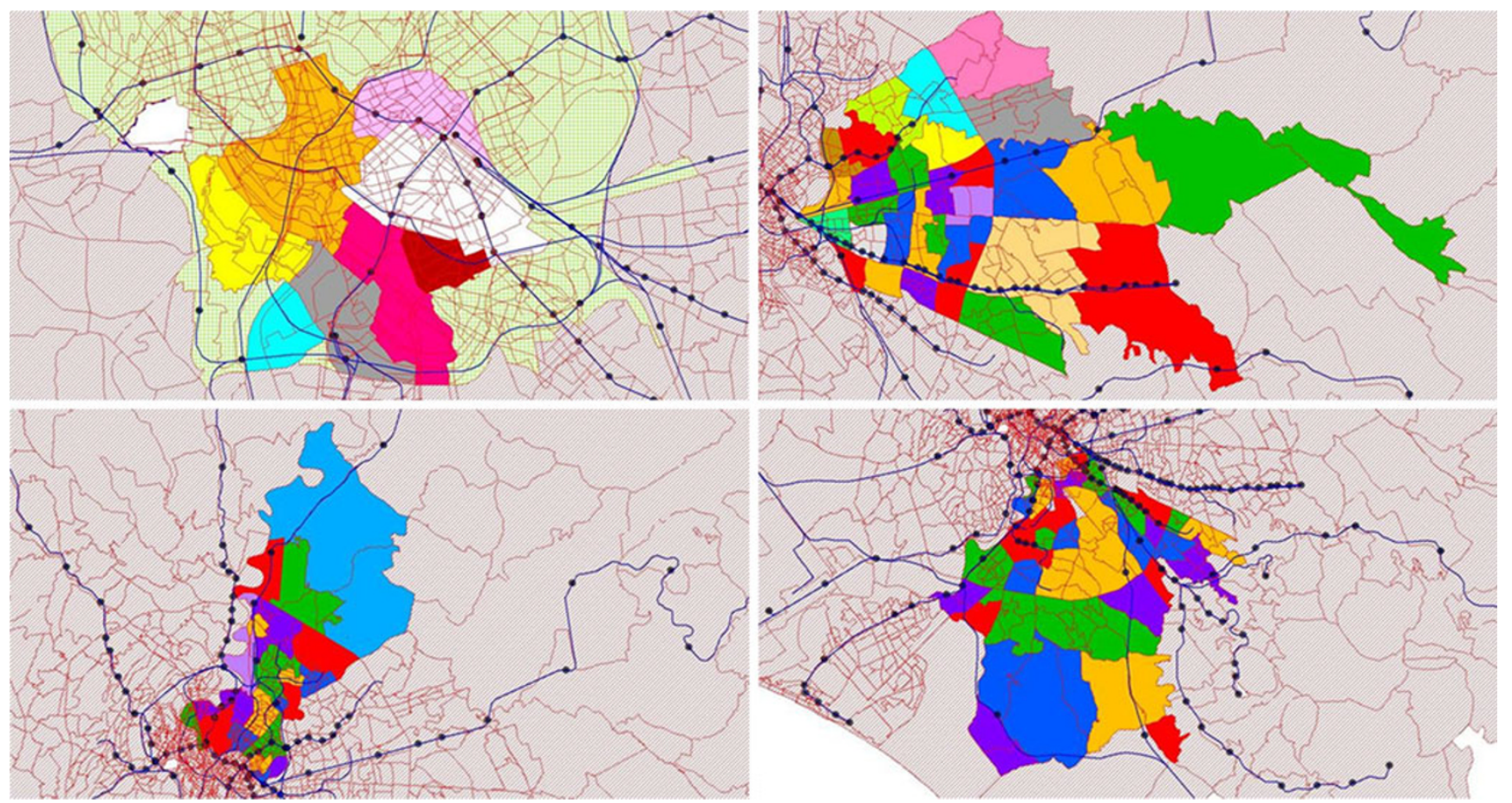

The data used in this and in the next section on private and public transport demand, for the morning peak hour, as well as other data related to demographic and socio-economic characteristics were obtained from the data bank of ATAC, the mobility agency for the city of Rome. The simulation of the multimodal network have been carried out using the software EMME for auto and transit assignment [15] while the estimation of the new public transport modal split was carried out using a modal choice model, specifically calibrated for the context of the urban area of Rome. It is based on the difference of total travel times using private or transit network and it also takes into account the specific capacity of public transport service to be attractive (high speed, high frequency and high reliability). In particular, the new public transport demand $d_{p u b}^{\text {od }}$ can be computed as:

$d_{p u b}^{o d}=d^{o d}-d_{p r}^{o d}$

Fig. 5 GIS maps of Rome districts, rail lines and stops 
Table 3 Land use and mobility indicators range for Rome traffic zones

\begin{tabular}{|c|c|c|c|c|c|c|c|}
\hline & \multirow[t]{2}{*}{ Population } & \multirow[t]{2}{*}{ Employees } & \multirow[t]{2}{*}{ Pop/ha } & \multirow[t]{2}{*}{ Emp/ha } & \multicolumn{2}{|c|}{ Transit modal split [\%] } & \multirow[t]{2}{*}{ Rail stops } \\
\hline & & & & & Generation & Attraction & \\
\hline Minimum value & 163 & 48 & 0.04 & 0.008 & 2.34 & 0.10 & 0 \\
\hline Average value & 17,452 & 7,834 & 66 & 32 & 26.84 & 18.72 & 2 \\
\hline Maximum value & 77,927 & 57,306 & 256 & 342 & 54.33 & 61.62 & 7 \\
\hline
\end{tabular}

where the private automobile demand $d_{p r}^{o d}$ derives from:

$d_{p r}^{o d}=\frac{d^{o d}}{\left(1+e^{\beta^{t} t_{p r}^{o d}+\beta^{t} t_{p u b}^{o d}+\beta^{c} c^{o d}+\beta^{a f t} a f f+C S A_{p r} \cdot A S A_{p r}}\right)}$

where

$d^{\text {od }} \quad$ total origin-destination transport demand

$t_{p r}^{o d} \quad$ travel time between origin $o$ and destination

$d$ using automobile

$t_{p u b}^{o d} \quad$ travel time between origin $o$ and destination

$d$ using public transport

$c^{o d} \quad$ monetary cost between origin $o$ and destination $d$

aff capacity of public transport service to be attractive between origin $o$ and destination $d$ (dummy variable)

$A S A_{p r} \quad$ alternative specific attribute for private transport

$\beta^{t}, \beta^{c}, \beta^{\text {aff }}, \quad$ coefficients of the corresponding attributes $C S A_{p r}$

Multiple linear regression using the least squares method is employed to calibrate the parameters of the model. The goodness of fit was assessed using the rhosquared statistic with a value of 0.28 while the $T$-test was used to verify the statistical significance of the different attributes used.

3.1 Infrastructural and land-use evolution scenarios for the Roman urban area

Different scenarios have been simulated to understand the possible evolution of the transit demand share in the Roman urban area. A infrastructural scenario has been proposed increasing the mass rapid transit system, while so called land-use scenarios has been proposed based on the development of areas with higher density of residences and activities. In particular, the three scenarios related to the temporal horizon of 2020 are so characterized:

1. scenario 1 with supply modifications compared to the current state according to the plans of the local administration;
2. scenario 2 in which 12 "transit villages" have been created grouping residences, increasing the population density in these areas up to 300 persons/ha;

3. scenario 3 in which 5 "transit villages" have been created grouping activities, increasing the employee density in these areas up to 250 employees/ha.

The local administration plans (scenario 1) foresee 2 new additional metro lines plus the extensions of the previous ones, modifying only the supply side. In addition, 11 new rapid feeder services corridors are provided in order to improve the feeder services to the future metro network which, however, remains substantially a radial network.

From the simulation of the first scenario (Table 1), with an increase in the metropolitan network from 36 to $76 \mathrm{~km}$ and the insertion of 11 new rapid feeder services corridors, the transit demand share increases by only $5 \%$ when compared to the current state, although the metro service coverage reaches more than two million people and, in terms of trips attracted, more than the $50 \%$ of the total trips within Rome. Therefore, the construction of new metro lines, despite the very large financial budget and the very long time for the project realization, seems to not produce significant

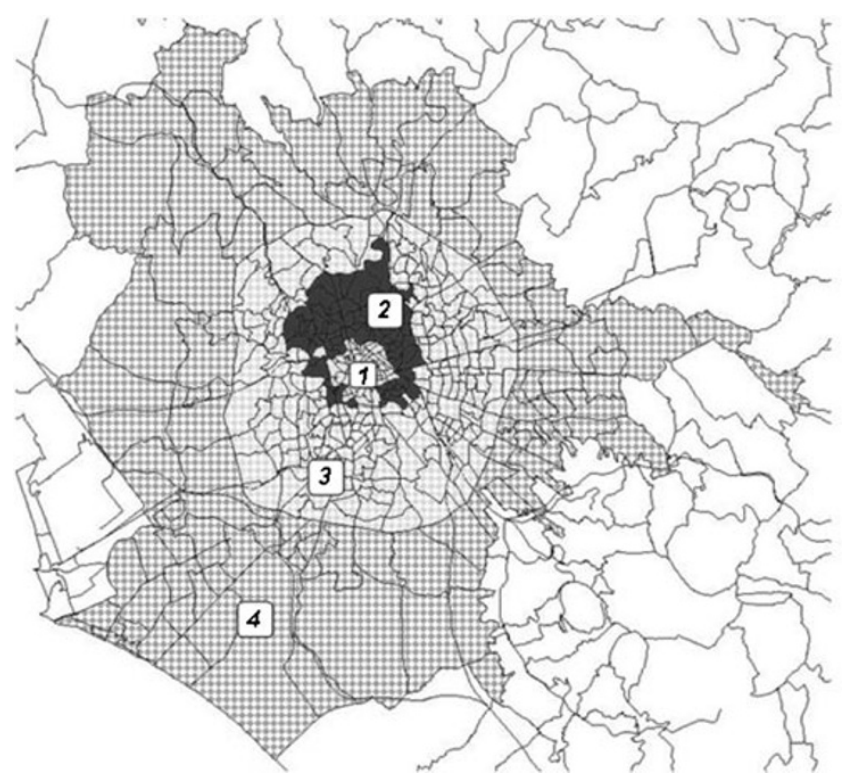

Fig. 6 Subdivision of the urban area of Rome in 4 macro-zones 
Table 4 Land use and mobility characteristics in the 4 macro areas of Rome (1)

\begin{tabular}{llllll}
\hline Zone & Dimension [ha] & Inhabitants & Employees & Inhabitants [\%] & Employees [\%] \\
\hline 1 & 1,427 & 96,472 & 194,461 & $3.76 \%$ & $17.57 \%$ \\
2 & 3,327 & 300,344 & 239,570 & $11.72 \%$ & $21.64 \%$ \\
3 & 29,638 & $1,588,518$ & 527,690 & $61.98 \%$ & $47.67 \%$ \\
4 & 93,931 & 577,601 & 145,299 & $22.54 \%$ & $13.13 \%$ \\
\hline
\end{tabular}

impacts with respect to the evolution towards a more sustainable mobility system.

Operating in a complete different way, working on the land use characteristics (Table 2), thus removing the 11 feeder services corridors and realizing the so called "transit-villages" around some metro lines stops, does not produce considerable variation in the modal share. An interesting observation (Table 2) is that "transit-villages" [14] obtained grouping activities or grouping residences involve the same modal split of the infrastructural scenario (scenario 1). But, also under these scenarios, the results are not satisfying from the point of view of sustainability of the mobility system.

\section{Mobility and land-use characteristics in the Roman urban area}

A detailed analysis of the roman urban structure has been done in this section, in order to better understand the previously described results and to verify whether the trends and the observations made by numerous authors in the existing literature over the relationships between land use and transportation system are observed in the case study of Rome too.

It is also important to underline that Rome has to be seen as a very special and interesting urban area in which there is the overlapping of different phenomena: a quite compact central area compared to the surrounding zones characterized by very low densities, a level of automobile ownerships similar to American cities and a large diffusion of motorcycles as in many developing countries's cities.

A thorough analysis based on GIS tool (Fig. 5) has been performed considering 130 zones which represent the districts of Rome. These zones are derived from the grouping of the about 500 traffic zones used for the traffic model of the city of Rome. For each district zone, different indicators have been computed: (i) land-use indicators such as population, employees, population per hectare, employees per hectare; (ii) mobility indicators such as the transit modal split for generated trips and attracted trips, number of transit stops considering the seven rail lines and the two metro lines as reported in paragraph 3. A full report of indicators for each district zone is described in Table 9. Single indicator values are then adopted as basis for computing aggregated indicators that best describe the land-use and mobility system connection inside the urban area of Rome.

A general framework of the Roman urban characteristics is underlined by the range assumed by the single indicators of the 130 district zones (Table 3). On average, the land-use presents not so high values about density of population and employees (respectively $66 \mathrm{pop} / \mathrm{ha}$ and $32 \mathrm{emp} / \mathrm{ha}$ ), corresponding to low values of transit modal split especially for attracted trips (18.72\%). This situation seems to be even more critical when taking into account that only 58 and 39 zones exceed the average values of, respectively, population and employees reported in Table 3. The level of transit modal share seems to be also correlated with the level of supply: the maximum level of transit modal split corresponds to the maximum number of rail and metro stops within the zone.

In comparison to the subdivision of the urban area reported before (inside or outside the GRA), Rome can also be divided into 4 circular areas (Fig. 6): the city centre (zone 1), the area between the city centre and the "rail ring" (zone 2 ), the area between the "rail ring" and the GRA (zone 3), and the area outside the GRA (zone 4).

Population increases from zone 1 to zone 3 , while it decreases outside the GRA (Table 4). The same thing happens in terms of activities, reported as the number of employees, with the only difference that employees outside

Table 5 Land use and mobility characteristics in the 4 macro areas of Rome (2)

\begin{tabular}{lllllll}
\hline Zone & Inhabitants/ha & Employees/ha & Generated trips/ha & Attracted trips/ha & $\begin{array}{l}\text { Generation transit } \\
\text { modal share } \\
\text { modtraction share } \\
\text { monsit }\end{array}$ \\
\hline 1 & 68 & 136 & 15.5 & 60.5 & $40.78 \%$ & $52.29 \%$ \\
3 & 90 & 72 & 23.5 & 37.9 & $35.44 \%$ & $42.34 \%$ \\
4 & 54 & 18 & 10.3 & 8.5 & $29.34 \%$ & $19.67 \%$ \\
\hline
\end{tabular}


Fig. 7 Classification of traffic zones by number of attracted trips

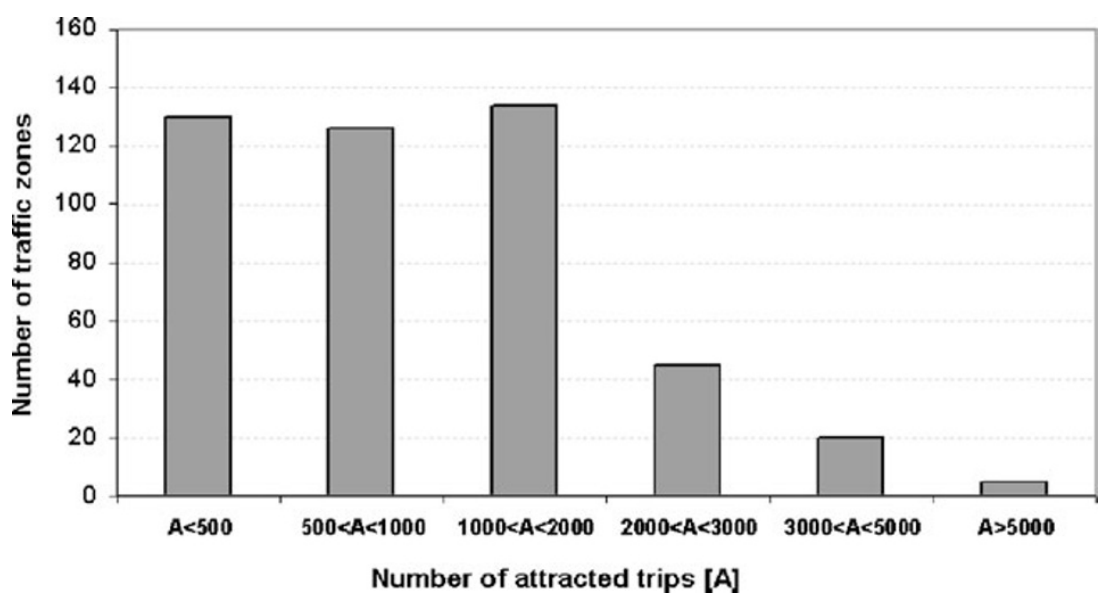

the GRA represent the lowest value of the whole urban area. Zones 3 and 4 (Table 4) represent the most populated areas (about $85 \%$ of the total amount) while the city centre (zone 1) has less than $4 \%$ of the total population. The activities are more uniformly distributed within the internal area of the city (zones 1 and 2 ) which is characterized by the presence of about $40 \%$ of the total amount of employees.

It is also important to compare these data with the extension of each macro-zone. In such case, zones 1 and 2 show higher population density values, which decrease strongly when moving outside the GRA (6 inhabitants/ha, Table 5). The same happens for activities, with higher density values recorded inside the rail ring while, when going outside, employees per hectare decrease to very low values (2 employees/ha, Table 5).

The characteristics previously underlined involve the presence of the maximum level of transport demand, as origin or destination, in the zone 3 inside the GRA. In such a case, a critical issue is related to the large size of this zone that produces a dispersion of the transport demand itself obstructing the appearance of high demand corridors. This condition, according to Beimborn et al. [6] represents one of the most important needs to develop high quality transit services. Such observation is valid also for the areas outside the GRA where a large amount of population translates into an important request of mobility in a very dispersed area.
This problematic situation are clearly expressed by the values of generation and attraction transit modal share in the different macro zones (Table 5). Lower values for transit modal split are observed for zone 4 and zone 3 , especially in terms of attracted trips. In regard to zone 4 , it is important to point out that there is a lack of high quality transit services because there are no metro lines but only three rail lines. In any case, the presence and the quality of transit services also seem to affect the generation and attraction transit modal shares which are decreasing from zone 1 to zone 4 (Table 5) following the current metro configuration (two radial lines inside the GRA with a unique interchange in the city centre). As described previously, this condition is particularly important for the transit modal split in attraction with a share of less than $10 \%$ outside the GRA and, on the contrary, with a value higher than $50 \%$ in the city centre (Table 5).

The generation or attraction rate of trips per hectare (Table 5) are quite low for almost all the four macro areas with the exception of the attraction rate for zone 1 (60.5 trips/ha), confirming the compact structure of the city centre.

The considerations made for zone 1 seem to underline the importance of the concentration of trip ends along transit service. In fact, a high number of activities concentrated around the stops of the metro network allows public transport to be an effective solution for travel to work.
Fig. 8 Different variation of built-up area density in New York and Los Angeles
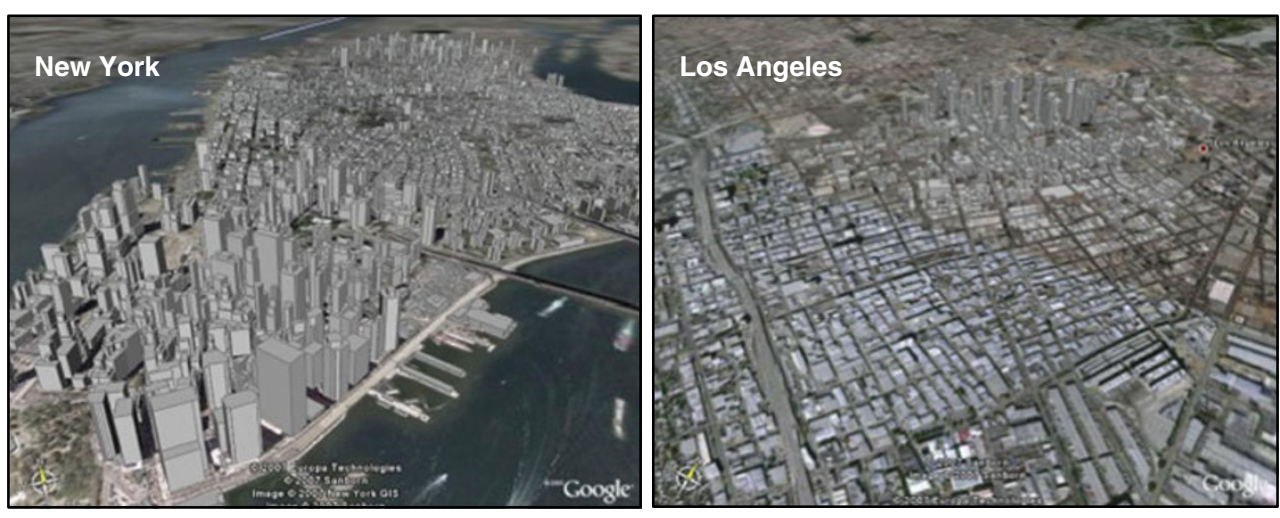
Table 6 Distribution of trips inside the coverage area of Rome metro network (2020) as a function of transit travel times $\left(\mathrm{TT}_{\mathrm{T}}\right)$ and travel times along the shortest path $\left(\mathrm{TT}_{\mathrm{SP}}\right)$

\begin{tabular}{lllll}
\hline & $\begin{array}{l}0 \leq \mathrm{TT}_{\mathrm{T}} / \\
\mathrm{TT}_{\mathrm{SP}} \leq 1\end{array}$ & $\begin{array}{l}1<\mathrm{TT}_{\mathrm{T}} / \\
\mathrm{TT}_{\mathrm{SP}} \leq 1,5\end{array}$ & $\begin{array}{l}1,5<\mathrm{TT}_{\mathrm{T}} / \\
\mathrm{TT}_{\mathrm{SP}} \leq 2\end{array}$ & $\begin{array}{l}\mathrm{TT}_{\mathrm{T}} / \\
\mathrm{TT}_{\mathrm{SP}}>2\end{array}$ \\
\hline $\begin{array}{c}\text { trips inside the metro } \\
\text { influence area [\%] }\end{array}$ & 23.4 & 3.5 & 17.9 & 55.2 \\
\hline
\end{tabular}

However, the situation of Rome is usually far from this type of land-use characteristics. Using a more detailed level of analysis, passing from the macro-zones to the single traffic zones (Fig. 7), it is possible to notice that most of the traffic zones are characterized by a very small number of attracted trips (lower than 2,000 persons/h). Only a small number of such zones ( $5 \%$ of the total amount of traffic-zones) have a number of attracted trips greater than 3,000 persons/h.

The sprawl of the urban area of Rome, as indicated by the data reported before, can be formally computed using the Gini coefficient (GC), a statistical index usually adopted to measure the dispersion of the values observed relative to a certain variable (in this case the density in an area). This is one of the most commonly used measure of inequality and the coefficient varies between 0 and 1 that, respectively, reflect complete equality and complete inequality. It can be computed as:

$G C=\frac{1}{n}\left(n+1-2 \frac{\sum_{i=1}^{n}(n+1-i) y_{i}}{\sum_{i=1}^{n} y_{i}}\right)$

where:

n traffic zones

y density

In the case of Rome, the Gini coefficient has been evaluated both in relation to the residences and the activities, obtaining the following values: $\mathrm{GC}$ (residences) $=0.48$ and
$\mathrm{GC}($ activities $)=0.62$. Such values can be evaluated by comparison with the Gini coefficient measured, by Eidlin [11], for metropolitan areas such as Los Angeles (GC(residences $)=0.65)$ or New York $(\mathrm{GC}($ residences $)=0.77)$. Roman data seems comparable to Los Angeles' data representing the classic example of urban sprawl with a Central Business District (CBD) of limited importance and a very low value of transit modal split (6.7\% for work trips, [11]). On the other hand, New York, which is the most important "transit metropolis" (26.6\% transit modal split for work trips, [11]) in the United States due to the presence of wellstructured CBDs with high density of activities (Fig. 8), has an higher value of the Gini coefficient, even if it has a lower average value of population density (3,376 inhab/square mile) than Los Angeles (4,372 inhab/square mile).

The previous analysed data about land use allows to identify some aspects correlated with the results obtained in the infrastructural scenario (scenario 1) described in section 3. Other important remarks result by comparing the transport demand characteristics and the metro network configuration. From the point of view of transport demand, it is essential to underline that the large increase in service coverage observed in scenario 1 (more than 2 million people residing in the future metro basin) does not correspond to a large increase in the number of public transport users. This means that the transport demand distribution can be defined as having a many-to-many configuration and not a many-toone (trips with destination the city centre) and, therefore, the planned development of transit system has to be considered inconsistent with respect to land use evolution. In fact, the metro network remains a radial network that permits high quality services for trips in radial direction while penalizes traversal movements also if the origin and the destination points are located along the metro lines. This element can be seen (Table 6) also by comparing transit travel times $\left(\mathrm{TT}_{\mathrm{T}}\right)$ with auto travel times along the shortest paths $\left(\mathrm{TT}_{\mathrm{SP}}\right)$. The travel times are obtained as results of the simulation of the multimodal network using the software EMME [15].
Fig. 9 Relation between activities density and transit modal split for Rome traffic zones

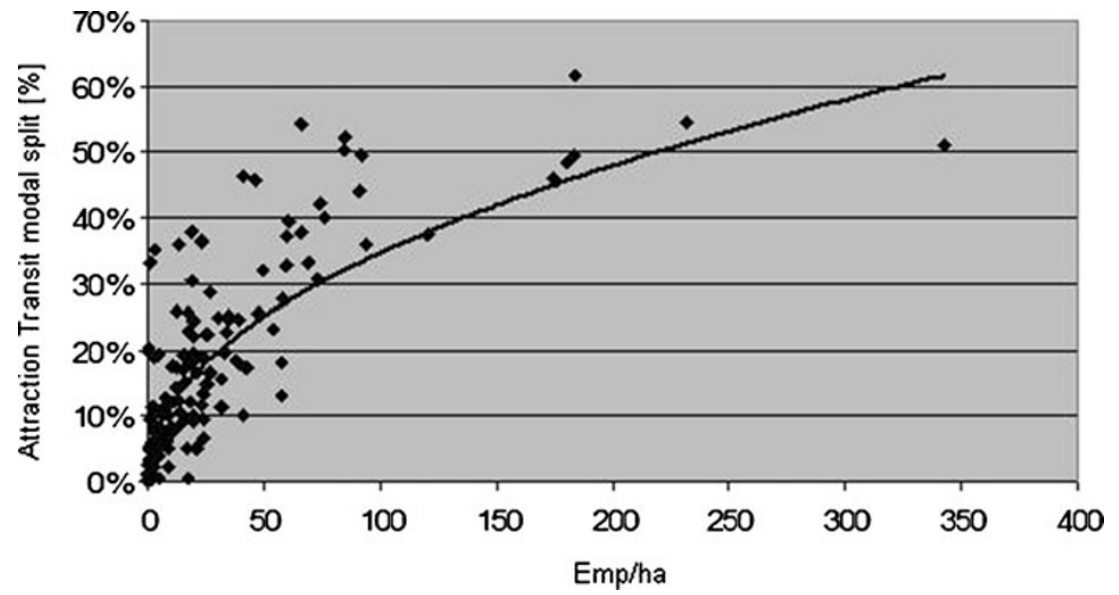


Fig. 10 Relation between population density and transit modal split for Rome traffic zones

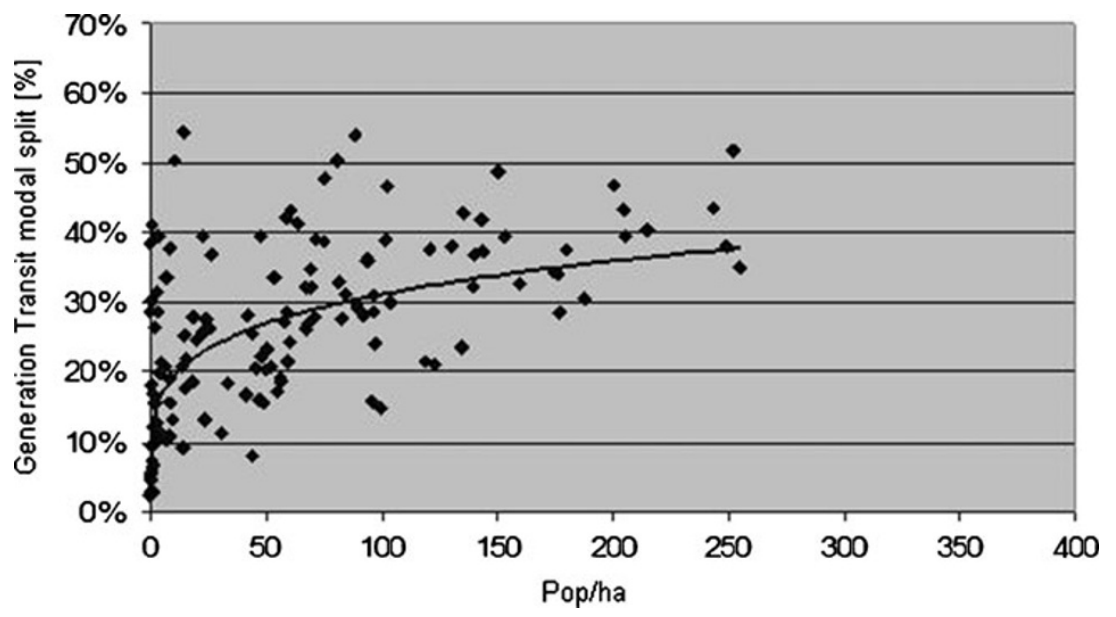

Only $23.4 \%$ of trips inside the coverage area (about 95.000 trips) can use the metro network with an advantage while transit travel times are more than double the travel times along the shortest paths for more than $50 \%$ of these trips. The other demand potentially involved by the transit system, demand with trip origin or destination in the coverage area of the metro network ( $42.8 \%$ of the total demand), reports an average transit travel time of $40 \mathrm{~min}$, a very high value when compared with the average travel time computed for the private transport $(20 \mathrm{~min})$.

From the other point of view, working on land-use, creating "transit villages" as reported in literature and increasing the transit modal split by only $+4 \div 5 \%$, shows that this action alone is not able to significantly modify the usual mobility habits. The results of scenario 2 and scenario 3 (Table 2) also show that grouping activities with only 5 "transit villages" is more effective than creating 12 "transit villages" by grouping residences.

This specific element is underlined both at macro-level analysis (Rome macro-zones, Table 4 and Table 5) and at districts level analysis. Figure 9 and Fig. 10 show, for the Roman case, the stronger relationships between density of population and employees and transit modal split. In particular, this correlation is, as reported before, more evident for the attracted trips (best fitting curve with rhosquared equal to 0.53) than for the generated trips (best fitting curve with rho-squared equal to 0.41 ), especially for low density, there is an high variation of the transit modal share.

Table 7 Generation average transit modal split and standard deviation respect to distance to rail stop

\begin{tabular}{lllll}
\hline Transit modal split & \multicolumn{4}{l}{ Distance to rail stop [m] } \\
\cline { 2 - 5 } & $<500$ & $500-1000$ & $1000-1500$ & $>1500$ \\
\hline Average & $35.45 \%$ & $21.80 \%$ & $18.96 \%$ & $8.69 \%$ \\
St. Dev. & $8.80 \%$ & $11.49 \%$ & $1.13 \%$ & $3.89 \%$ \\
\hline
\end{tabular}

The difference between concentrating generated trips and attracted trips is mainly due to the impact of the accessegress phase to/from the mass transit system. While the access is considered an easi phase, because the trip from the origin zone to the transit stop can be done using different modes (walk, bike \& ride, park \& ride, kiss \& ride etc.), the egress phase from the final stop to the destination is constrained by the transit and pedestrian network defined around the destination zone.

Of course, to promote the mass transit system is important to correctly define the dimension of the "transit village", because it influences the access/egress phase. In the case study of Rome, the "transit village" has a dimension of about $500 \mathrm{~m}$ of radius as reported in the literature [14].

The value of this variable is confirmed in the Roman case by the analysis of Table 7 and Table 8 . Starting from the current situation, the transit modal share in generation and in attraction of the roman traffic zones are compared to the average distance from the mass rapid transit stops. For distances lower than $500 \mathrm{~m}$ the transit modal split is larger than $35 \%$ for generated trips and is about $30 \%$ for attracted trips. On the other hand, for distances higher than $1 \mathrm{~km}$, the average value and the standard deviation of the transit modal split decrease in a very important way.

At the end of the analyses, it is clear that the dispersion of residences and activities, essentially due to the lack of effective land use policy, is one of the most important reasons in explaining the results obtained from the simulations of the Roman case. Moreover, results underline that

Table 8 Attraction average transit modal split and standard deviation respect to distance to rail stop

\begin{tabular}{lllll}
\hline Transit modal split & \multicolumn{4}{l}{ Distance to rail stop [m] } \\
\cline { 2 - 5 } & $<500$ & $500-1000$ & $1000-1500$ & $>1500$ \\
\hline Average & $29.29 \%$ & $12.07 \%$ & $7.86 \%$ & $3.03 \%$ \\
St. Dev. & $14.68 \%$ & $10.94 \%$ & $2.51 \%$ & $2.05 \%$ \\
\hline
\end{tabular}


Table 9 Analysis of districts in the Roman urban area

\begin{tabular}{|c|c|c|c|c|c|c|c|}
\hline \multirow[t]{2}{*}{ District zone } & \multirow[t]{2}{*}{ Population } & \multirow[t]{2}{*}{ Employees } & \multirow[t]{2}{*}{ Pop/ha } & \multirow[t]{2}{*}{ Emp/ha } & \multicolumn{2}{|c|}{ Transit modal split [\%] } & \multirow[t]{2}{*}{ Rail stops } \\
\hline & & & & & Generation & Attraction & \\
\hline Centro storico & 22,854 & 57,306 & 72 & 180 & $39.06 \%$ & $48.56 \%$ & 1 \\
\hline Trastevere & 12,540 & 11,884 & 69 & 66 & $32.27 \%$ & $37.75 \%$ & \\
\hline Aventino & 7,401 & 7,050 & 48 & 45 & $39.49 \%$ & $45.93 \%$ & 2 \\
\hline Testaccio & 8,446 & 2,405 & 143 & 41 & $41.92 \%$ & $46.31 \%$ & \\
\hline Esquilino & 31,756 & 57,021 & 102 & 184 & $46.54 \%$ & $61.62 \%$ & 7 \\
\hline XX Settembre & 9,006 & 48,288 & 64 & 342 & $41.40 \%$ & $51.12 \%$ & 2 \\
\hline Celio & 3,948 & 8,035 & 59 & 120 & $42.10 \%$ & $37.42 \%$ & \\
\hline Area Archeologica & 521 & 2,472 & 3 & 13 & $31.54 \%$ & $35.91 \%$ & 1 \\
\hline Villaggio Olimpico & 2,794 & 2,609 & 24 & 23 & $27.59 \%$ & $36.61 \%$ & \\
\hline Parioli & 19,888 & 14,089 & 97 & 68 & $30.93 \%$ & $33.21 \%$ & 1 \\
\hline Flaminio & 12,484 & 12,995 & 90 & 93 & $29.35 \%$ & $35.90 \%$ & \\
\hline Salario & 23,276 & 33,491 & 121 & 174 & $37.53 \%$ & $46.00 \%$ & \\
\hline Trieste & 50,886 & 17,274 & 176 & 60 & $34.11 \%$ & $39.62 \%$ & \\
\hline Villa Ada & 1,044 & 1,257 & 4 & 4 & $28.62 \%$ & $19.39 \%$ & 3 \\
\hline Villa Borghese & 475 & 2,550 & 3 & 18 & $39.59 \%$ & $37.97 \%$ & 1 \\
\hline Nomentana & 39,721 & 24,830 & 136 & 85 & $42.72 \%$ & $50.33 \%$ & 2 \\
\hline S. lorenzo & 9,191 & 3,347 & 180 & 66 & $37.57 \%$ & $54.35 \%$ & 1 \\
\hline Università & 905 & 23,681 & 9 & 232 & $37.77 \%$ & $54.75 \%$ & 1 \\
\hline Montesacro & 16,143 & 3,997 & 97 & 24 & $28.73 \%$ & $19.00 \%$ & \\
\hline Val Melaina & 38,009 & 4,574 & 119 & 14 & $21.64 \%$ & $14.53 \%$ & \\
\hline Montesacro alto & 33,190 & 7,784 & 135 & 32 & $23.63 \%$ & $15.65 \%$ & \\
\hline Fidene & 11,278 & 1,402 & 100 & 12 & $14.89 \%$ & $8.43 \%$ & \\
\hline Serpentara & 27,023 & 6,069 & 48 & 11 & $22.35 \%$ & $12.05 \%$ & 2 \\
\hline Casal Boccone & 9,229 & 2,737 & 15 & 5 & $17.77 \%$ & $8.16 \%$ & \\
\hline Conca d'Oro & 19,808 & 4,098 & 160 & 33 & $32.69 \%$ & $19.56 \%$ & \\
\hline Sacco Pastore & 9,902 & 1,381 & 215 & 30 & $40.52 \%$ & $25.00 \%$ & 1 \\
\hline Tufello & 15,423 & 2,174 & 177 & 25 & $28.56 \%$ & $22.53 \%$ & \\
\hline Aeroporto Urbe & 2,122 & 6,176 & 5 & 14 & $21.36 \%$ & $10.65 \%$ & 2 \\
\hline Settebagni & 4,238 & 2,314 & 9 & 5 & $19.08 \%$ & $6.17 \%$ & 1 \\
\hline Bufalotta & 4,298 & 849 & 3 & 1 & $11.90 \%$ & $4.82 \%$ & \\
\hline Tor San Giovanni & 620 & 629 & 0 & 0 & $5.42 \%$ & $1.10 \%$ & \\
\hline Casal Bertone & 17,187 & 7,386 & 92 & 40 & $28.06 \%$ & $17.81 \%$ & \\
\hline Casal Bruciato & 23,693 & 4,639 & 94 & 18 & $36.50 \%$ & $18.08 \%$ & 1 \\
\hline Tiburtino Nord & 21,540 & 4,158 & 61 & 12 & $43.18 \%$ & $26.02 \%$ & 4 \\
\hline Tiburtino Sud & 26,331 & 7,407 & 94 & 26 & $35.97 \%$ & $16.66 \%$ & \\
\hline San Basilio & 27,274 & 11,725 & 44 & 19 & $25.57 \%$ & $9.37 \%$ & \\
\hline Tor Cervara & 2,518 & 1,540 & 7 & 4 & $10.48 \%$ & $5.54 \%$ & \\
\hline Pietralata & 15,486 & 5,899 & 70 & 27 & $34.88 \%$ & $28.62 \%$ & 3 \\
\hline Csal dè pazzi & 28,816 & 7,917 & 58 & 16 & $27.12 \%$ & $19.18 \%$ & 1 \\
\hline Sant'Alessandro & 7,467 & 1,841 & 7 & 2 & $20.85 \%$ & $5.33 \%$ & \\
\hline Settecamini & 8,714 & 21,553 & 8 & 21 & $15.51 \%$ & $4.94 \%$ & \\
\hline Tor Pignattara & 46,337 & 10,562 & 206 & 47 & $39.41 \%$ & $25.72 \%$ & 6 \\
\hline Casilino & 11,725 & 3,435 & 60 & 17 & $28.73 \%$ & $22.98 \%$ & 3 \\
\hline Quadraro & 18,895 & 2,446 & 130 & 17 & $38.15 \%$ & $25.76 \%$ & 1 \\
\hline Gordiani & 44,435 & 6,717 & 250 & 38 & $37.98 \%$ & $18.36 \%$ & \\
\hline Centocelle & 53,558 & 10,238 & 175 & 33 & $34.22 \%$ & $22.68 \%$ & 2 \\
\hline Alessandrino & 25,898 & 3,462 & 83 & 11 & $27.58 \%$ & $14.25 \%$ & 3 \\
\hline
\end{tabular}


Table 9 (continued)

\begin{tabular}{|c|c|c|c|c|c|c|c|}
\hline \multirow[t]{2}{*}{ District zone } & \multirow[t]{2}{*}{ Population } & \multirow[t]{2}{*}{ Employees } & \multirow[t]{2}{*}{ Pop/ha } & \multirow[t]{2}{*}{ Emp/ha } & \multicolumn{2}{|c|}{ Transit modal split $[\%]$} & \multirow[t]{2}{*}{ Rail stops } \\
\hline & & & & & Generation & Attraction & \\
\hline Tor Sapienza & 12,452 & 4,949 & 59 & 24 & $21.59 \%$ & $9.69 \%$ & 1 \\
\hline La Rustica & 10,248 & 3,007 & 57 & 17 & $19.23 \%$ & $5.00 \%$ & \\
\hline Tor Tre Teste & 12,443 & 2,049 & 96 & 16 & $15.90 \%$ & $9.49 \%$ & \\
\hline Casetta Mistica & 679 & 1,411 & 2 & 4 & $26.44 \%$ & $5.45 \%$ & 1 \\
\hline CD Centocelle & 1,440 & 261 & 7 & 1 & $33.63 \%$ & $11.44 \%$ & \\
\hline Omo & 565 & 6,634 & 2 & 23 & $15.60 \%$ & $6.65 \%$ & \\
\hline Torre Spaccata & 14,745 & 1,812 & 84 & 10 & $31.25 \%$ & $17.69 \%$ & \\
\hline Torre Maura & 19,452 & 5,721 & 71 & 21 & $27.94 \%$ & $16.64 \%$ & 2 \\
\hline Tor Vergata & 17,771 & 4,218 & 20 & 5 & $24.52 \%$ & $10.59 \%$ & \\
\hline Acqua Vergine & 3,289 & 2,304 & 3 & 2 & $12.80 \%$ & $8.56 \%$ & 2 \\
\hline Lunghezza & 29,411 & 4,562 & 23 & 4 & $13.18 \%$ & $8.19 \%$ & 1 \\
\hline Torre Angela & 77,927 & 11,712 & 47 & 7 & $16.00 \%$ & $12.86 \%$ & 7 \\
\hline Borghesiana & 34,006 & 5,878 & 14 & 2 & $9.28 \%$ & $7.60 \%$ & 6 \\
\hline San Vittorino & 6,202 & 776 & 2 & 0 & $6.62 \%$ & $2.92 \%$ & \\
\hline Tuscolano Nord & 21,879 & 9,953 & 201 & 91 & $46.80 \%$ & $49.69 \%$ & 3 \\
\hline Tuscolano Sud & 47,956 & 15,737 & 150 & 49 & $48.68 \%$ & $31.88 \%$ & 4 \\
\hline Tor Fiscale & 1,454 & 665 & 16 & 7 & $22.03 \%$ & $11.62 \%$ & \\
\hline Appio & 28,055 & 10,410 & 205 & 76 & $43.21 \%$ & $40.01 \%$ & \\
\hline Latino & 22,728 & 5,480 & 144 & 35 & $37.41 \%$ & $24.64 \%$ & \\
\hline Don Bosco & 56,465 & 11,951 & 252 & 53 & $51.69 \%$ & $23.19 \%$ & 6 \\
\hline Appio Claudio & 30,693 & 6,652 & 89 & 19 & $53.81 \%$ & $19.53 \%$ & \\
\hline Quarto miglio & 9,499 & 2,980 & 19 & 6 & $18.74 \%$ & $5.81 \%$ & 1 \\
\hline Pignatelli & 6,753 & 1,903 & 68 & 19 & $26.94 \%$ & $10.03 \%$ & \\
\hline Lucrezia Romana & 2,461 & 2,554 & 14 & 15 & $54.33 \%$ & $17.10 \%$ & \\
\hline Osteria del curato & 23,116 & 5,210 & 104 & 23 & $30.08 \%$ & $13.38 \%$ & 1 \\
\hline Romanina & 5,392 & 8,432 & 26 & 41 & $26.32 \%$ & $10.03 \%$ & \\
\hline Gregna & 5,576 & 3,239 & 15 & 9 & $25.20 \%$ & $7.04 \%$ & \\
\hline Barcaccia & 4,890 & 1,008 & 10 & 2 & $13.34 \%$ & $3.47 \%$ & \\
\hline Morena & 26,165 & 6,555 & 34 & 8 & $18.51 \%$ & $5.04 \%$ & 1 \\
\hline Ciampino & 259 & 633 & 1 & 2 & $30.29 \%$ & $2.15 \%$ & 1 \\
\hline Ostiense & 8,013 & 7,804 & 76 & 74 & $47.81 \%$ & $42.27 \%$ & 1 \\
\hline Valco San Paolo & 8,440 & 2,948 & 54 & 19 & $33.51 \%$ & $30.51 \%$ & \\
\hline Garbatella & 45,972 & 21,862 & 154 & 73 & $39.40 \%$ & $30.83 \%$ & 4 \\
\hline Navigatori & 5,101 & 4,331 & 67 & 57 & $32.24 \%$ & $18.19 \%$ & \\
\hline Tor Marancia & 28,022 & 8,188 & 67 & 20 & $26.33 \%$ & $22.05 \%$ & \\
\hline Tre Fontane & 11,785 & 11,173 & 60 & 57 & $24.32 \%$ & $13.19 \%$ & 1 \\
\hline Grottaperfetta & 15,381 & 9,346 & 52 & 32 & $20.74 \%$ & $11.28 \%$ & \\
\hline Appia Antica Nord & 1,941 & 2,230 & 1 & 1 & $18.16 \%$ & $6.09 \%$ & 1 \\
\hline Appia Antica Sud & 394 & 615 & 0 & 1 & $5.33 \%$ & $0.10 \%$ & \\
\hline Eur & 18,785 & 41,137 & 26 & 58 & $36.89 \%$ & $27.76 \%$ & 4 \\
\hline Torrino & 38,215 & 17,238 & 50 & 23 & $20.23 \%$ & $11.52 \%$ & \\
\hline Laurentino & 25,019 & 8,875 & 51 & 18 & $23.52 \%$ & $12.09 \%$ & \\
\hline Cecchignola & 15,417 & 9,977 & 13 & 9 & $20.71 \%$ & $10.18 \%$ & \\
\hline Mezzocamino & 5,767 & 1,102 & 11 & 2 & $50.49 \%$ & $18.82 \%$ & 2 \\
\hline Spinaceto & 25,244 & 4,501 & 57 & 10 & $18.72 \%$ & $8.19 \%$ & \\
\hline Vallerano & 13,919 & 5,303 & 4 & 1 & $11.68 \%$ & $2.98 \%$ & \\
\hline Decima & 4,815 & 828 & 1 & 0 & $9.56 \%$ & $2.49 \%$ & 1 \\
\hline
\end{tabular}


Table 9 (continued)

\begin{tabular}{|c|c|c|c|c|c|c|c|}
\hline \multirow[t]{2}{*}{ District zone } & \multirow[t]{2}{*}{ Population } & \multirow[t]{2}{*}{ Employees } & \multirow[t]{2}{*}{ Pop/ha } & \multirow[t]{2}{*}{ Emp/ha } & \multicolumn{2}{|c|}{ Transit modal split [\%] } & \multirow[t]{2}{*}{ Rail stops } \\
\hline & & & & & Generation & Attraction & \\
\hline Porta Medaglia & 1,715 & 217 & 1 & 0 & $3.11 \%$ & $0.10 \%$ & \\
\hline Castel Romano & 235 & 825 & 0 & 1 & $4.95 \%$ & $3.22 \%$ & 1 \\
\hline Santa Palomba & 530 & 2,191 & 1 & 4 & $7.43 \%$ & $0.41 \%$ & \\
\hline Malafede & 7,846 & 673 & 18 & 2 & $27.92 \%$ & $11.32 \%$ & 1 \\
\hline Acilia Nord & 21,317 & 2,186 & 23 & 2 & $25.73 \%$ & $11.31 \%$ & 1 \\
\hline Acilia Sud & 21,317 & 2,186 & 23 & 2 & $39.38 \%$ & $10.84 \%$ & \\
\hline Palocco & 23,018 & 3,724 & 23 & 4 & $27.58 \%$ & $7.86 \%$ & \\
\hline Ostia Antica & 9,211 & 1,492 & 4 & 1 & $19.76 \%$ & $9.64 \%$ & 1 \\
\hline Ostia Nord & 42,956 & 6,998 & 75 & 12 & $38.86 \%$ & $17.42 \%$ & 1 \\
\hline Ostia Sud & 35,972 & 6,758 & 81 & 15 & $50.46 \%$ & $19.19 \%$ & 3 \\
\hline Castel Fusano & 1,129 & 327 & 1 & 0 & $41.06 \%$ & $20.39 \%$ & 2 \\
\hline Infernetto & 10,740 & 1,253 & 9 & 1 & $10.92 \%$ & $5.08 \%$ & \\
\hline Castel Porziano & 259 & 48 & 0 & 0 & $2.34 \%$ & $0.36 \%$ & \\
\hline Marconi & 33,987 & 7,879 & 256 & 59 & $35.00 \%$ & $37.21 \%$ & \\
\hline Portuense & 29,537 & 6,051 & 123 & 25 & $21.15 \%$ & $14.77 \%$ & 1 \\
\hline Pian Due Torri & 25,725 & 3,579 & 140 & 19 & $32.27 \%$ & $24.36 \%$ & 1 \\
\hline Trullo & 28,271 & 4,824 & 42 & 7 & $16.88 \%$ & $11.36 \%$ & 1 \\
\hline Magliana & 1,576 & 19,539 & 1 & 17 & $2.83 \%$ & $0.58 \%$ & 1 \\
\hline Corviale & 14,546 & 2,827 & 31 & 6 & $11.39 \%$ & $7.85 \%$ & \\
\hline Ponte Galeria & 6,037 & 2,915 & 1 & 1 & $12.07 \%$ & $5.30 \%$ & 1 \\
\hline Colli Portuensi & 36,256 & 15,699 & 98 & 42 & $24.20 \%$ & $17.28 \%$ & \\
\hline Buon Pastore & 30,743 & 8,642 & 46 & 13 & $20.59 \%$ & $12.32 \%$ & \\
\hline Pisana & 3,012 & 3,495 & 4 & 4 & $10.40 \%$ & $4.02 \%$ & \\
\hline Gianicolense & 55,279 & 17,454 & 188 & 59 & $30.42 \%$ & $32.73 \%$ & 2 \\
\hline Massimina & 6,093 & 1,165 & 44 & 8 & $8.14 \%$ & $2.26 \%$ & \\
\hline Pantano di Grano & 2,816 & 1,569 & 1 & 0 & $4.44 \%$ & $1.31 \%$ & 1 \\
\hline Villa Pamphili & 163 & 73 & 1 & 1 & $16.75 \%$ & $19.63 \%$ & \\
\hline Prati & 17,954 & 32,216 & 102 & 183 & $38.97 \%$ & $49.60 \%$ & 2 \\
\hline Della Vittoria & 25,775 & 28,805 & 82 & 91 & $32.83 \%$ & $43.97 \%$ & 2 \\
\hline Eroi & 20,453 & 7,097 & 243 & 84 & $43.56 \%$ & $52.47 \%$ & 3 \\
\hline Aurelio sud & 25,413 & 9,787 & 90 & 35 & $29.63 \%$ & $25.08 \%$ & 1 \\
\hline Val Cannuta & 29,620 & 11,324 & 42 & 16 & $28.20 \%$ & $15.00 \%$ & 2 \\
\hline Fogaccia & 26,005 & 3,616 & 55 & 8 & $17.27 \%$ & $6.08 \%$ & \\
\hline Aurelio Nord & 18,717 & 5,178 & 141 & 39 & $36.89 \%$ & $24.56 \%$ & 2 \\
\hline Casalotti di Boccea & 15,422 & 2,264 & 50 & 7 & $15.55 \%$ & $7.60 \%$ & \\
\hline Boccea & 4,574 & 1,784 & 1 & 0 & $6.22 \%$ & $3.47 \%$ & \\
\hline
\end{tabular}

planning a system of huge "transit villages" is not a sufficient condition for increasing transit demand unless the transit oriented developments are connected among themselves with an effective transit system. In this situation, the lack of high demand corridors and huge attraction poles results in a many-to-many need for trips: as a consequence the existing network and also the future one are not able to create the so called "network-effect", resulting in high travel times, due to time losses for transfers and above all due to the mandatory crossing through the city centre for the interchange between lines, due to the configuration of the network itself.

\section{Conclusions}

The paper analyses elements and criteria related to the connection between land use and public transport in order to achieve a more sustainable mobility system. This require actions to reduce the need of travel, to encourage modal 
shift, to reduce trip lengths and to increase efficiency of transport system. Public transport could play an important role to solve part of the needs previously reported. To realize such objective, some possible actions have been identified: a) the improvement of the transit network increasing the mass rapid transit lines; b) the development of areas with higher density of residences and activities. The effectiveness of these actions was carried out through a detailed analysis of the related literature and by simulating these actions in the real world case of the city of Rome in Italy, an interesting urban area with overlapping different phenomena.

The results of the test carried out allow to offer some remarks about the role, the importance, and the impact of the interaction between land use policy and transportation planning. An important role is assumed by the density. The density has to be high in order to concentrate trips along an high capacity, high speed and high reliable transit service, so increasing the accessibility at the start and at the end of the trip and, as a consequence, the "door-to-door" travel speed. Especially the accessibility at destination seems to be correlated with the use of transit system and it depends on the transit and pedestrian alternatives defined in the destination zone. However, the analysis clearly points out that the development of well-designed urban patterns, oriented to receive transit services, is not sufficient, by itself, to produce substantial advances in terms of sustainability of transport system. These improvements do depend on the land use characteristics but, at the same time, they depend on the configuration of the transit network which connects the different districts in the best way (Table 9).

In other words, these actions could be effective only if they are planned within a complex unique system that helps the synergic development of the effects of the single actions proposed.

Future research could be oriented to identify a planning methodology able to reproduce the interaction between the development of land use and public transport systems. In particular, the planning process could be able to identify the "land use" levels (value and distribution of density of residences and activities) consistent with the capacity at disposal of each element of the transport system. This criteria is based on the consideration that there is a temporal and budget gap between the construction of residences and offices and the realization of public transport infrastructures that require a very long time and a very large budget.
Open Access This article is distributed under the terms of the Creative Commons Attribution License which permits any use, distribution, and reproduction in any medium, provided the original author(s) and the source are credited.

\section{References}

1. ATAC SpA (2009) Carta dei servizi del Trasporto Pubblico a Roma

2. Badoe DA, Miller EJ (2000) Transportation-land-use interaction: empirical findings in North America and their implications for modeling. Transport Res D 5:235-263

3. Banister D (2000) Sustainable urban development and transport - a Eurovision for 2020. Transp Rev 20(1):113-130

4. Banister D (2005) Unsustainable transport: city transport in the new century. Routledge, London

5. Banister D (2006) Transport, urban form and economic growth. Paper presented at the ECMT Regional Round Table 137. Berkeley

6. Beimborn E, Rabinowitz H, Mrotek C, Gugliotta P, Yan S (1992) Transit-based approach to land use design. Transp Res Rec 1349:107-114

7. Bernick M, Cervero R (1997) Transit villages in the 21st century. McGraw-Hill, New York

8. Buehler R (2011) Determinants of transport mode choice: a comparison of Germany and the USA. J Transp Geogr 19:644-657

9. Calthorpe P (1993) The next American metropolis. Princeton Architectural Press, New York

10. Cervero R (1998) The transit metropolis: a global inquiry. Island Press, Washington

11. Eidlin E (2005) The worst of all worlds. Transport Res Rec: Journal of the Transportation Research Board, No.1902:1-9

12. Ewing R, Cervero R (2001) Travel and the built environment - a synthesis. Transport Res Rec: Journal of the Transportation Research Board, No.1780:87-114

13. Facchinetti M (2007) Intorno al nodo. Pitagora Editrice, Bologna

14. Gori S, Nigro M, Petrelli M (2006) Transit-based land use and transport network design. Proceedings of the EWGT2006 Joint Conferences

15. INRO Consultants Inc (1989) Emme/2 users manual

16. Mees P (2009) Density and transport mode choice in Australian, Canadian and US cities. 32nd Australasian Transport Research Forum Auckland, ATRF

17. Newman PWG, Kenworthy JR (1996) The land use-transport connection. Land Use Pol 13(1):1-22

18. Schlossberg M (2004) From TIGER to audit instruments - measuring neighborhood walkability with street data based on geographic information systems. Transport Res Rec: Journal of the Transportation Research Board, N.1982, pp 48-56

19. Schlossberg M, Brown N (2004) Comparing transit-oriented development sites by walkability indicators. Transport Res Rec: Journal of the Transportation Research Board, N.1887, pp 34-42

20. Sinha KC (2003) Sustainability and urban public transportation. J Transport Eng, pp 331-341

21. Sung H, Ho J (2011) Transit-oriented development in a high-density city: identifying its association with transit ridership in Seoul, Korea. Cities 28:70-82 